\title{
Embedded Spiral Microstrip Implantable Antenna
}

\author{
Wei Huang ${ }^{1}$ and Ahmed A. Kishk ${ }^{2}$ \\ ${ }^{1}$ Department of Electrical Engineering, University of Mississippi, Oxford, MS 38677, USA \\ ${ }^{2}$ Department of Electrical and Computer Engineering, Concordia University, Montreal, QC, Canada H3G 1 M8
}

Correspondence should be addressed to Wei Huang, irene.w.huang@gmail.com

Received 14 February 2011; Accepted 4 May 2011

Academic Editor: Shyh-Kang Jeng

Copyright (C) 2011 W. Huang and A. A. Kishk. This is an open access article distributed under the Creative Commons Attribution License, which permits unrestricted use, distribution, and reproduction in any medium, provided the original work is properly cited.

A miniaturized embedded spiral-shaped microstrip antenna simulated within a block of $2 / 3$ human muscle phantom is designed for implanted cardiac pacemaker. The new design not only achieves the good matching at the required $403 \mathrm{MHz}$ but also obtains $57 \%$ size reduction over the existing design. The reflection coefficients are measured in both free space and in the human-tissueequivalent dielectric liquid. Good agreement is achieved between simulated results and the experimental results.

\section{Introduction}

In their early stage of development, implanted medical devices such as cardiac pacemakers or implantable defibrillators, which use inductive coupling for communication, could only transmit their data within a few inches range. In the recent years, telecommunications has played a more and more important role in implantable device systems. For these advanced systems, a more efficient implanted antenna is required to enable two-way communication between the implanted device and an external device.

The implanted antenna should be compact, lightweight, and able to download a patient's health information from the implanted device as well as to upload various parameters from an external device. It is also necessary to protect the human body from the heat, physical damage, or short circuiting of the antenna. Moreover, it should be designed to operate in the $402-405 \mathrm{MHz}$ range as required by the Federal Communication Commission (FCC) for Medical Implant Communications Services (MICS) [1]. Antenna size is also important. The typical dimension of a cardiac pacemaker battery pack is about $30.7 \times 41 \times 9.5 \mathrm{~mm}^{3}$ as shown in Figure 1 [2]. The size and weight of a cardiac pacemaker have become smaller and lighter due to the advances in implantable electronic device technology; therefore, one of the biggest challenges in designing an implantable system is to miniaturize the implanted antenna. Microstrip antennas are good candidates because they are flexible in design and shape. Also, there are many miniaturization techniques available for them. A miniature Hilbert PIFA (planar inverted-F antenna) has been discussed in [3] for biotelemetry. In [4], dual-resonant $\pi$-shape with double L-strips PIFA with size $22.5 \times 22.5 \mathrm{~mm}^{2}$ is designed. In $[5,6]$, both an embedded spiral and serpentine antennas are designed with size $16.8 \times$ $26.8 \mathrm{~mm}^{2}$.

\section{Antenna Geometry}

Here, an embedded spiral-shaped microstrip antenna is designed as shown in Figure 2. The antenna with width $(W) 1.8 \mathrm{~mm}$ and lengths $\left(L_{3}\right) 11 \mathrm{~mm},\left(L_{4}\right) 17.4 \mathrm{~mm},\left(L_{5}\right)$ $3.6 \mathrm{~mm}$, and $\left(L_{6}\right) 4.9 \mathrm{~mm}$ is designed with high dielectric substrate and superstrate Rogers RT/duroid $6010\left(\varepsilon_{r}=10.2\right.$, $\delta=0.0023)$. Both the substrate and superstrate have the same size, $\left(L_{1}\right) 11.9 \mathrm{~mm} \times\left(L_{2}\right) 18.2 \mathrm{~mm} \times(t) 1.9 \mathrm{~mm}$. The superstrate can protect against the heat from the antenna radiation. The meandered line physically lengthens the microstrip line in the fixed 2D dimension. The lengthened current path can bring the resonance frequency to lower range. A $50 \mathrm{Ohm}$ coaxial probe is used to feed the antenna. Also, a shorting pin, which is located at $\left(L_{7}\right) 3.4 \mathrm{~mm}$ away from the head of the spiral microstrip, acts as an additional tuning factor to the imaginary part of antenna impedance. Table 1 lists the design parameters compared with the 


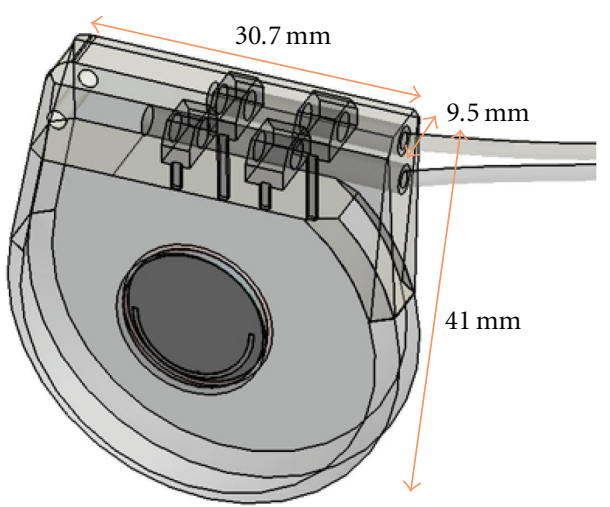

Figure 1: Typical dimensions of cardiac pacemaker battery pack [2].

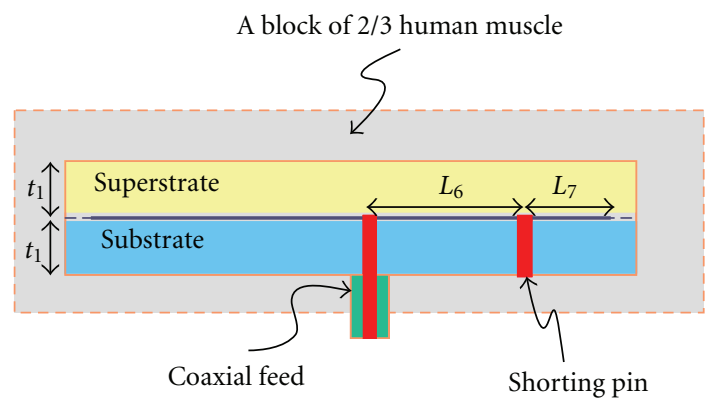

(a)

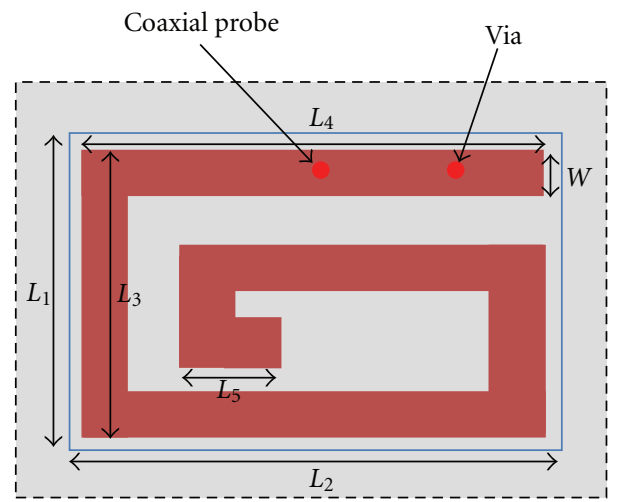

(b)

Figure 2: Geometry of embedded spiral-shaped microstrip implantable antenna, (a) side view, (b) top view.

existing design in [6]. About a $63 \%$ size reduction is achieved due to the higher-dielectric-constant material used.

\section{Simulation Results and Parametric Studies}

The antenna is designed using Ansoft high-frequency structure simulator (HFSS) [7] as shown in Figure 3. The antenna is simulated inside of a block of $2 / 3$ human muscle, which has $\varepsilon_{r}=42.807$ and $\sigma=0.6463 \mathrm{~S} / \mathrm{m}$ at $403 \mathrm{MHz}$. Here a block of $2 / 3$ human muscle is used since in reality human tissue contains not only muscle but also body fluid. Figure 3 shows that good matching is achieved at the required $403 \mathrm{MHz}$. If

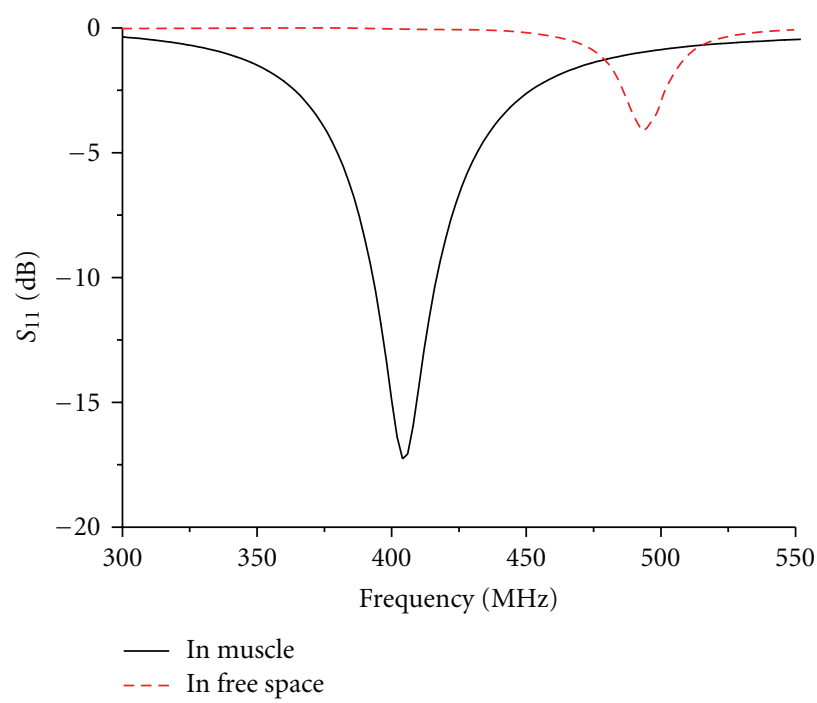

Figure 3: Simulated reflection coefficients in $2 / 3$ human muscle block and in free space.

TABLE 1: Design parameters of embedded spiral-shaped microstrip implantable antenna.

\begin{tabular}{lcc}
\hline Parameters & Design in [6] $(\mathrm{mm})$ & Our design $(\mathrm{mm})$ \\
\hline$L_{1}$ & 19.6 & 11.9 \\
$L_{2}$ & 29.6 & 18.2 \\
$L_{3}$ & 16.8 & 11.0 \\
$L_{4}$ & 26.6 & 17.4 \\
$L_{5}$ & 13.0 & 3.6 \\
$L_{6}$ & 7.7 & 4.9 \\
$L_{7}$ & 4.9 & 3.4 \\
$t_{1}$ & 3.0 & 1.9 \\
$t_{2}$ & 3.0 & 1.9 \\
$W$ & 2.8 & 1.8 \\
\hline Total size reduction & & $62.67 \%$ \\
\hline
\end{tabular}

the antenna is placed in free space, the resonant frequency increases to $489 \mathrm{MHz}$ while the matching deteriorates.

The results of parametric studies of different tail lengths $\left(L_{5}\right)$, shorting pin locations $\left(L_{7}\right)$, and different combinations of substrate and superstrate are shown in Figures 4(a)-4(c). It is noted that when the tail length $\left(L_{5}\right)$ increases, both the resonant frequency decreases and the magnitude of the reflection coefficient deteriorates. When the shorting pin moves away from the edge of the antenna, the resonance frequency increases while the magnitude of the reflection coefficient deteriorates. When material of lower permittivity, that is, Macor $\left(\varepsilon_{r}=6.03\right)$ or Teflon $\left(\varepsilon_{r}=2.1\right)$, is used as superstrate, as expected, the resonant frequency increases. Table 2 records the simulated radiating efficiencies for five different substrates and superstrates combinations obtained from HFSS. When the antenna is placed in free space, the radiating efficiencies in far field are obtained. When the antenna is placed in $2 / 3$ muscle block, the radiating 


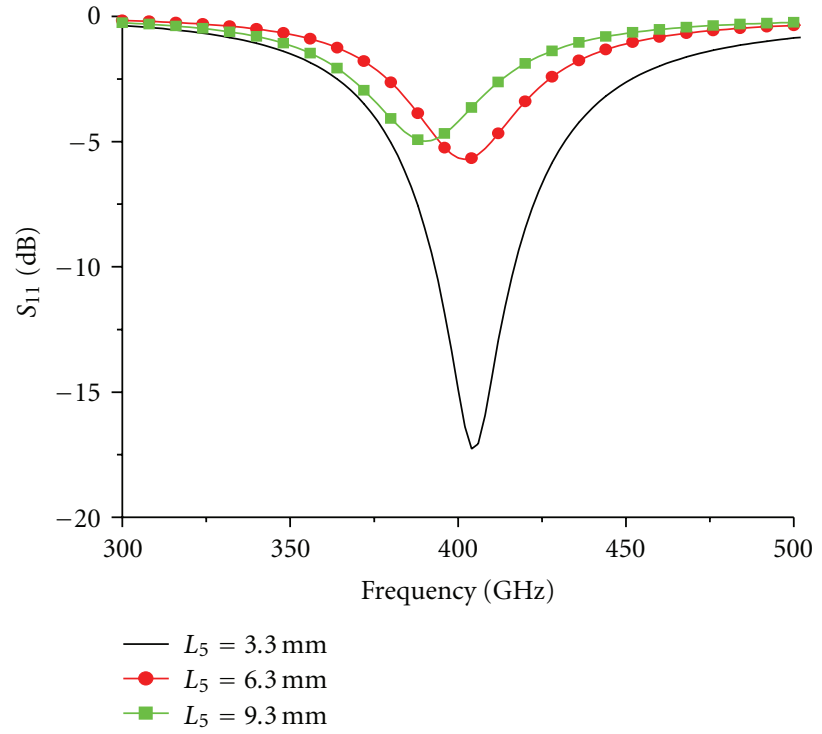

(a)

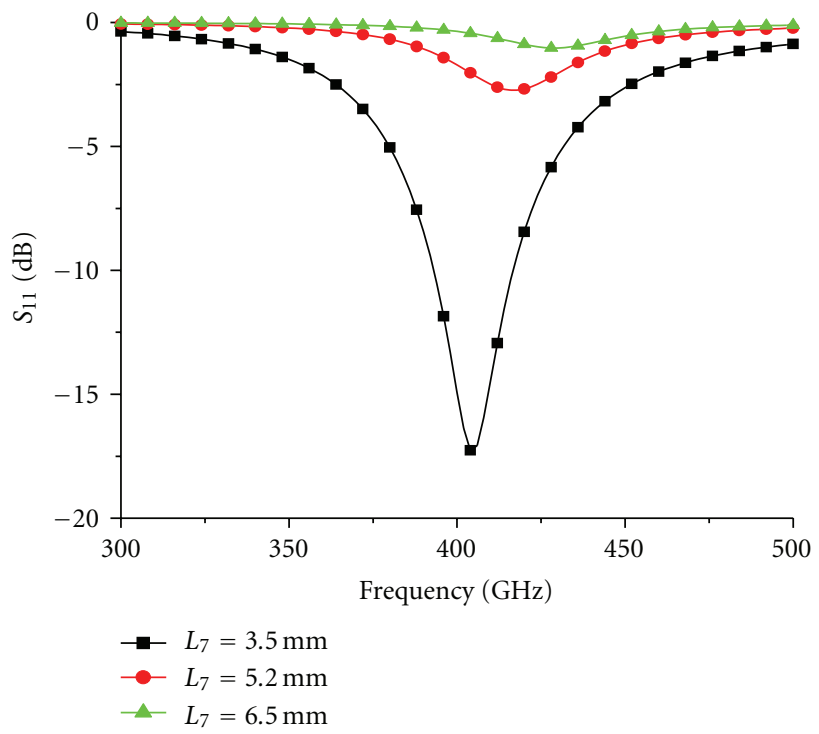

(b)

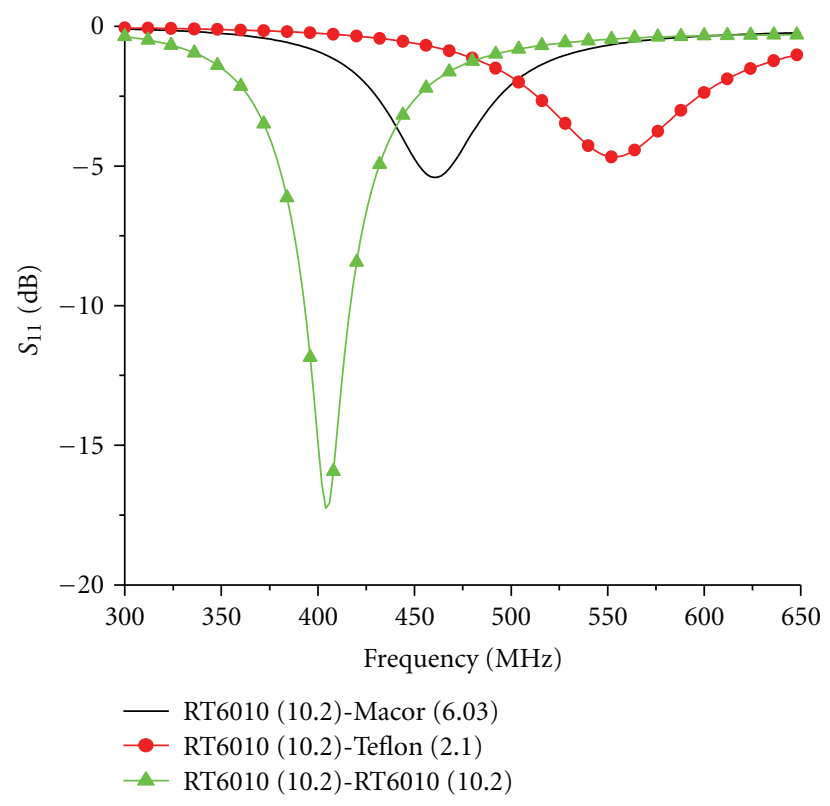

(c)

FIgURE 4: Parametric study of different (a) tail length, (b) shorting pin locations, and (c) combinations of substrate and superstrate.

efficiencies at 1 meter from the center of antenna are obtained. It can be found that when superstrate and substrate are both Rogers RT6010, the highest efficiencies are achieved in both cases.

When the antenna was assumed to deliver $1 \mathrm{~W}$, the 1 -g average specific absorption rate (SAR) distribution over the $x-y$ plane $(z=$ the interface between the antenna superstrate and $2 / 3$ human muscle) is given in Figure 5. It can be noticed that the peak SAR is $2.749 \mathrm{~W} / \mathrm{Kg}$, which means to satisfy the regulated IEEE SAR limitation $(1.6 \mathrm{~W} / \mathrm{Kg})$, the delivered power should not exceed $5.8 \mathrm{~mW}$.

\section{Antenna Fabrication, Tissue-Equivalent Liquid, and Measurements}

In the experimental model, as shown in Figure 6(a), the embedded spiral-shaped microstrip implantable antenna is built by using Rogers material duroid $6010\left(\varepsilon_{r}=10.2, \tan \delta=\right.$ 0.0023 , thickness $=1.9 \mathrm{~mm}$ ). A $50 \mathrm{Ohms}$ coaxial cable with a SubMiniature version A (SMA) connector is used to excite the antenna. The shorted pin is made by a piece of copper wire with radius $0.3 \mathrm{~mm}$ and the same height as the substrate thickness with both ends soldered with top microstrip and 


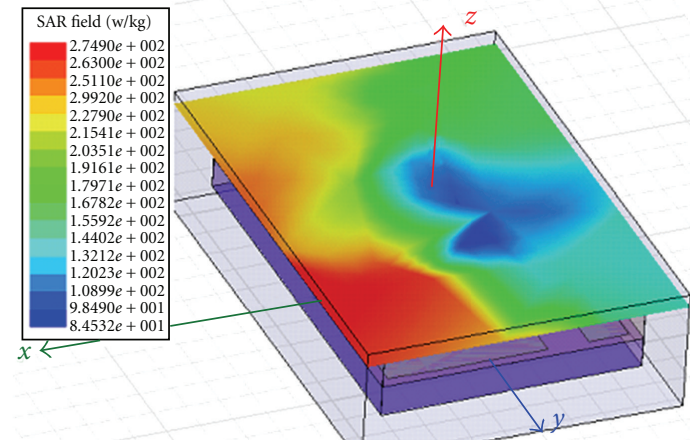

FIgURE 5: Simulated SAR distribution over the $x-y$ plane ( $z=$ the interface between the antenna superstrate and muscle block).

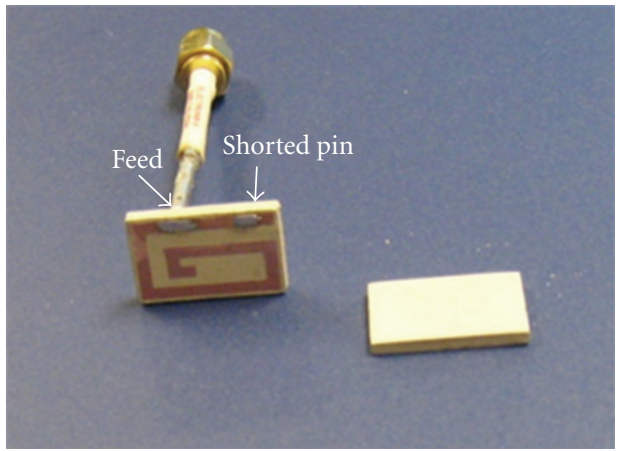

(a)

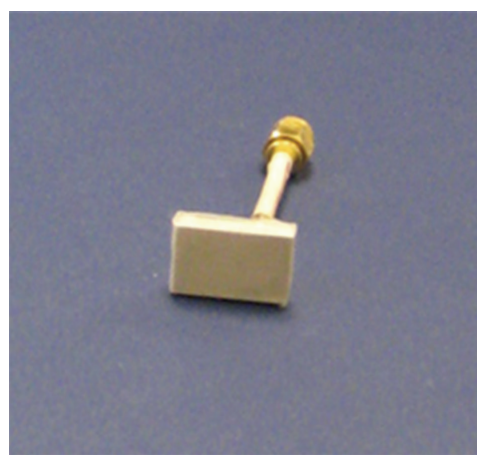

(b)

FIGURE 6: Fabricated embedded spiral-shaped microstrip implantable antenna: (a) individual pieces, (b) final prototype.

TABle 2: Calculated efficiency.

\begin{tabular}{lccc}
\hline Superstrate & Substrate & $\begin{array}{c}\text { Eff. in air } \\
\text { \%) at far } \\
\text { field }\end{array}$ & $\begin{array}{c}\text { Eff. in muscle (\%) at 1 m } \\
\text { from the center of antenna }\end{array}$ \\
\hline RT6010 & RT6010 & 96.82 & 16.1 \\
Macor & RT6010 & 82.47 & 4.47 \\
Teflon & RT6010 & 90.76 & 6.36 \\
RT6010 & Macor & 86.38 & 9.74 \\
RT6010 & Teflon & 92.089 & 9.62 \\
\hline
\end{tabular}

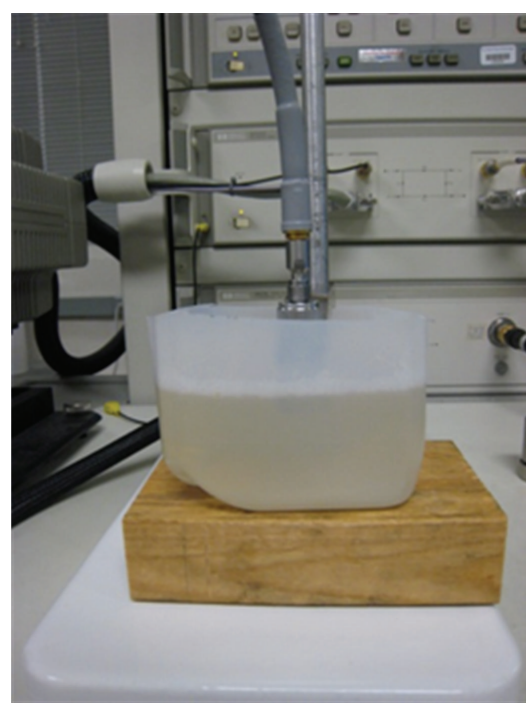

FIGURE 7: Experimental setup for measuring permittivity of tissueequivalent liquid.

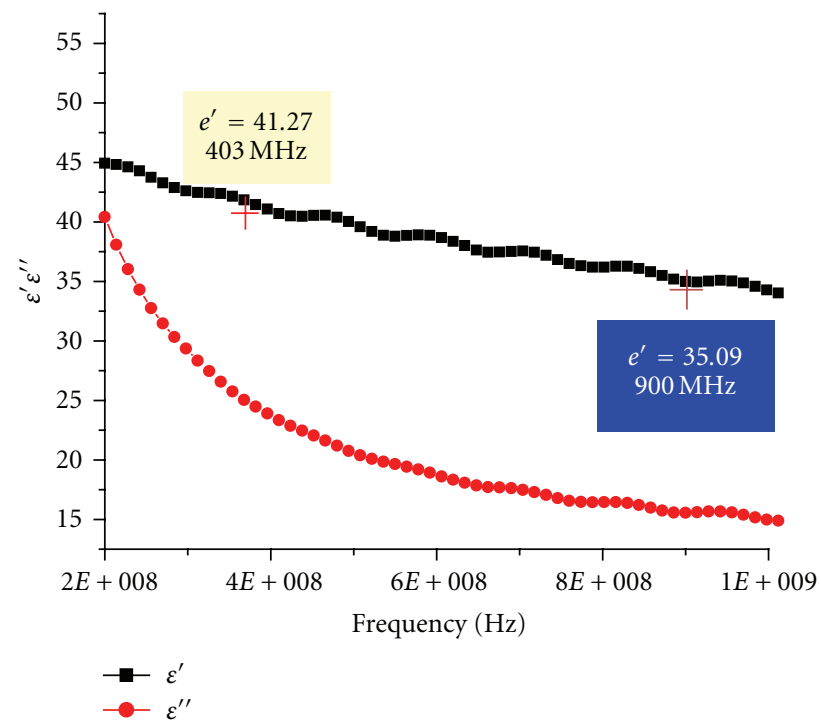

FIGURE 8: Measured permittivity of tissue-equivalent liquid.

bottom ground plane, respectively. Figure 6(b) shows the final prototype of the antenna when it is wrapped by a thin film, which has permittivity close to air.

The tissue-equivalent liquid, which is made from water, sugar, $\mathrm{NaCl}$, and cellulose cetylpyridinium chloride, and so forth [6], is used to simulate the $2 / 3$ human muscle block. Figure 7 demonstrates the experimental setup for measuring the permittivity of tissue-equivalent liquid by using HP 85070A dielectric probe kit, which controls the network analyzer to measure the complex reflection coefficient of the material under test and then converts the reflection coefficient into the complex permittivity of the material under test. Figure 8 shows the measured permittivity results. It can be found that, at $900 \mathrm{MHz}$, the real part of the permittivity is about 35.09 which is very close to the measured result given 


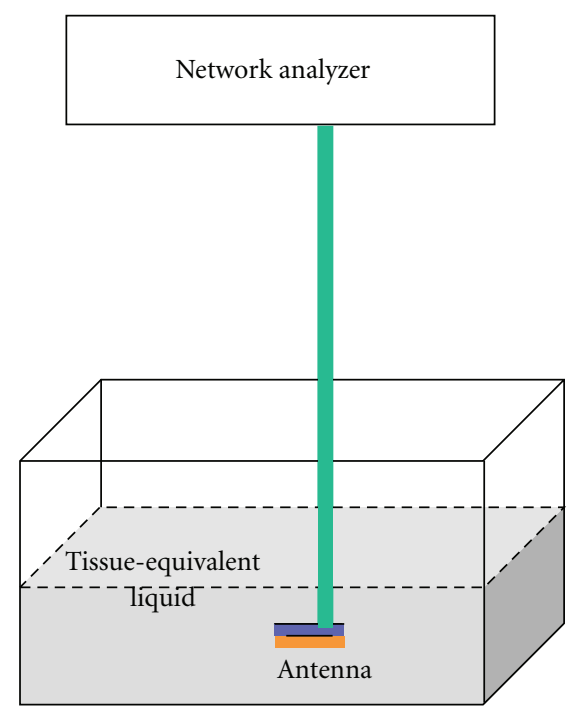

(a)

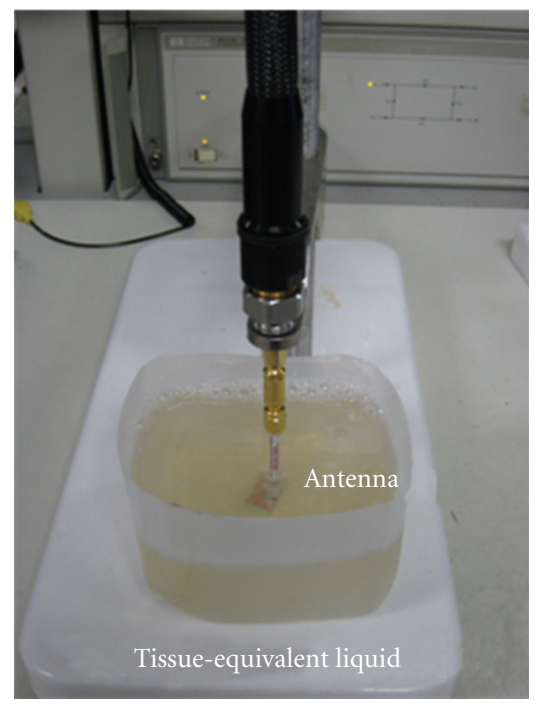

(b)

FIGURE 9: Experimental setup for measuring resonant frequencies of implantable antenna.

in [6]. From the same curve, at $403 \mathrm{MHz}$, the real part of the permittivity is 41.27 , which is lower than the permittivity of the $2 / 3$ human muscle $\left(\varepsilon_{r}=42.807\right)$ that we used in the simulation.

Figure 9 illustrates the experimental setup for measuring the resonant frequencies of implantable antenna. The antenna is positioned in a container filled with tissueequivalent liquid and connected to the HP $8510 \mathrm{C}$ vector network analyzer. The reflection coefficients are measured in both free space and in the tissue-equivalent liquid, as shown in Figure 10. It can be noticed that the measured reflection coefficient is well matched around $403 \mathrm{MHz}$ when the antenna is placed in the liquid. After adjusting the permittivity of the $2 / 3$ human muscle blocks in HFSS simulation to the same value as the measured value of the

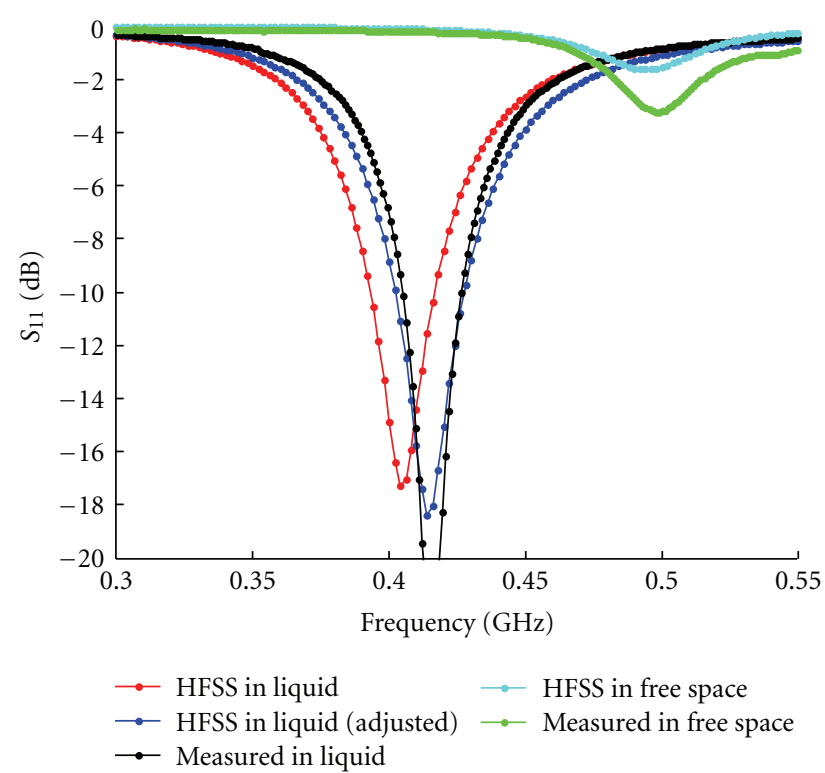

Figure 10: Measured resonant frequencies of implantable antenna in free space and in tissue-equivalent liquid.

tissue-equivalent liquid. Good agreement is achieved between simulated results and the experimental results.

\section{Conclusions}

A miniaturized embedded spiral-shaped microstrip antenna simulated within a block of $2 / 3$ human muscle phantom is designed for an implanted cardiac pacemaker. This novel design not only achieves good matching at the required $403 \mathrm{MHz}$ but also results in a $57 \%$ size reduction over the existing design. The reflection coefficients are measured in both free space and in the human-tissue-equivalent dielectric liquid. Good agreement is achieved between simulated results and the experimental results.

\section{Acknowledgment}

This work was supported by the National Science Foundation under Grant no. ECS-524293.

\section{References}

[1] http://wireless.fcc.gov/services/index.htm?job=service_home\& id=medical_implant.

[2] http://en.wikipedia.org/wiki/Artificial_pacemaker.

[3] M. Z. Azad and M. Ali, "A miniaturized implantable antenna for GPS application," in Proceedings of the IEEE Antennas and Propagation Society International Symposium, pp. 1103-1106, Albuquerque, NM, USA, July 2006.

[4] C.-M. Lee, C.-H. Luo, T.-C. Yo, and F.-J. Huang, "Dualresonant $\pi$-shape with double L-strips PIFA for implantable biotelemetry," Electronics Letters, vol. 44, no. 14, pp. 837-838, 2008.

[5] J. Kim and Y. Rahmat-Samii, "Planar inverted-F antennas on implantable medical devices: meandered type versus spiral type," Microwave and Optical Technology Letters, vol. 48, no. 3, pp. 567-572, 2006. 
[6] P. Soontornpipit, C. M. Furse, and Y. C. Chung, "Design of implantable microstrip antenna for communication with medical implants," IEEE Transactions on Microwave Theory and Techniques, vol. 52, no. 8, pp. 1944-1951, 2004.

[7] Ansoft High Frequency Structure Simulator User's Guide, Version 10.0, Ansoft Corporation, Pittsburgh, Pa, USA, 2005. 

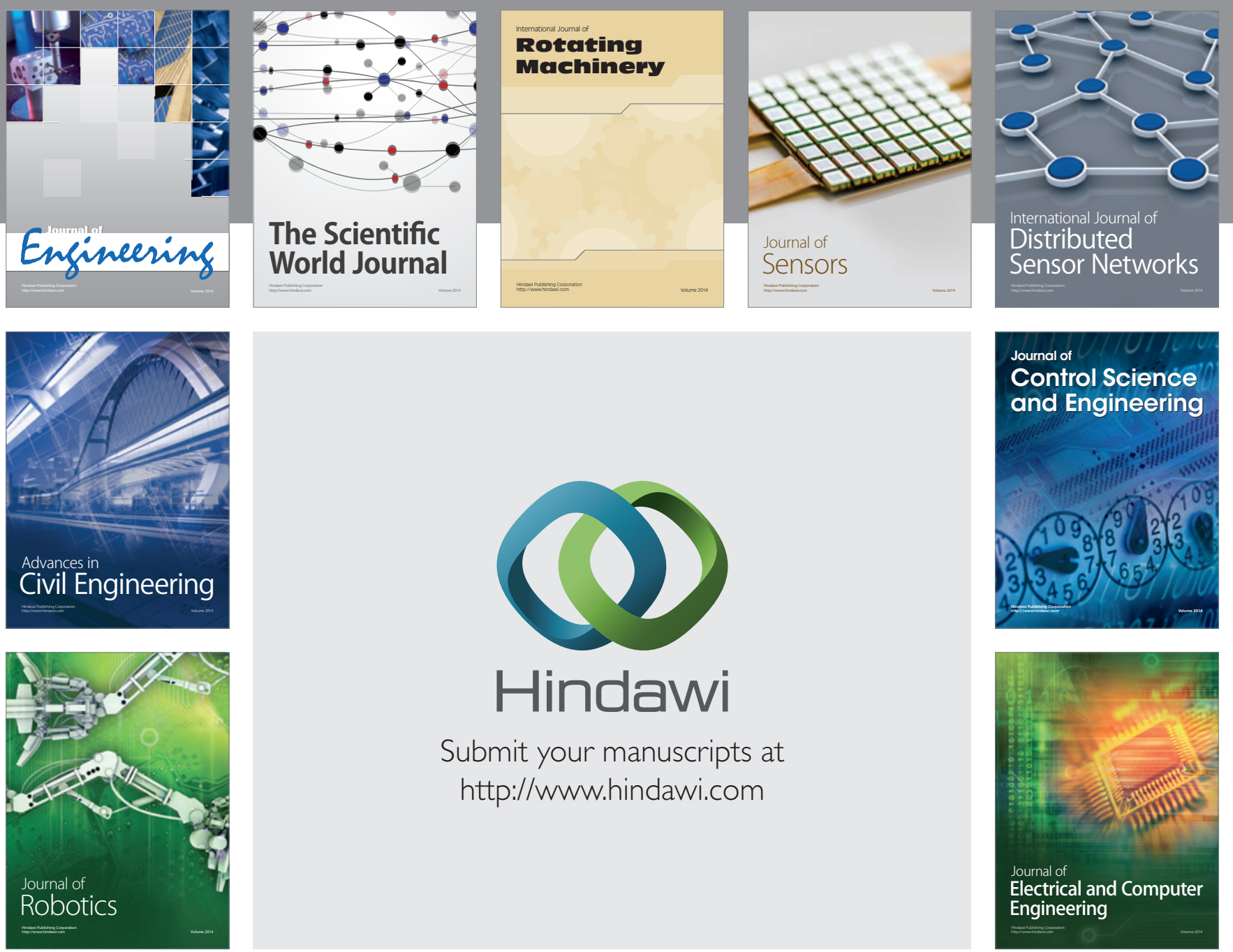

Submit your manuscripts at

http://www.hindawi.com
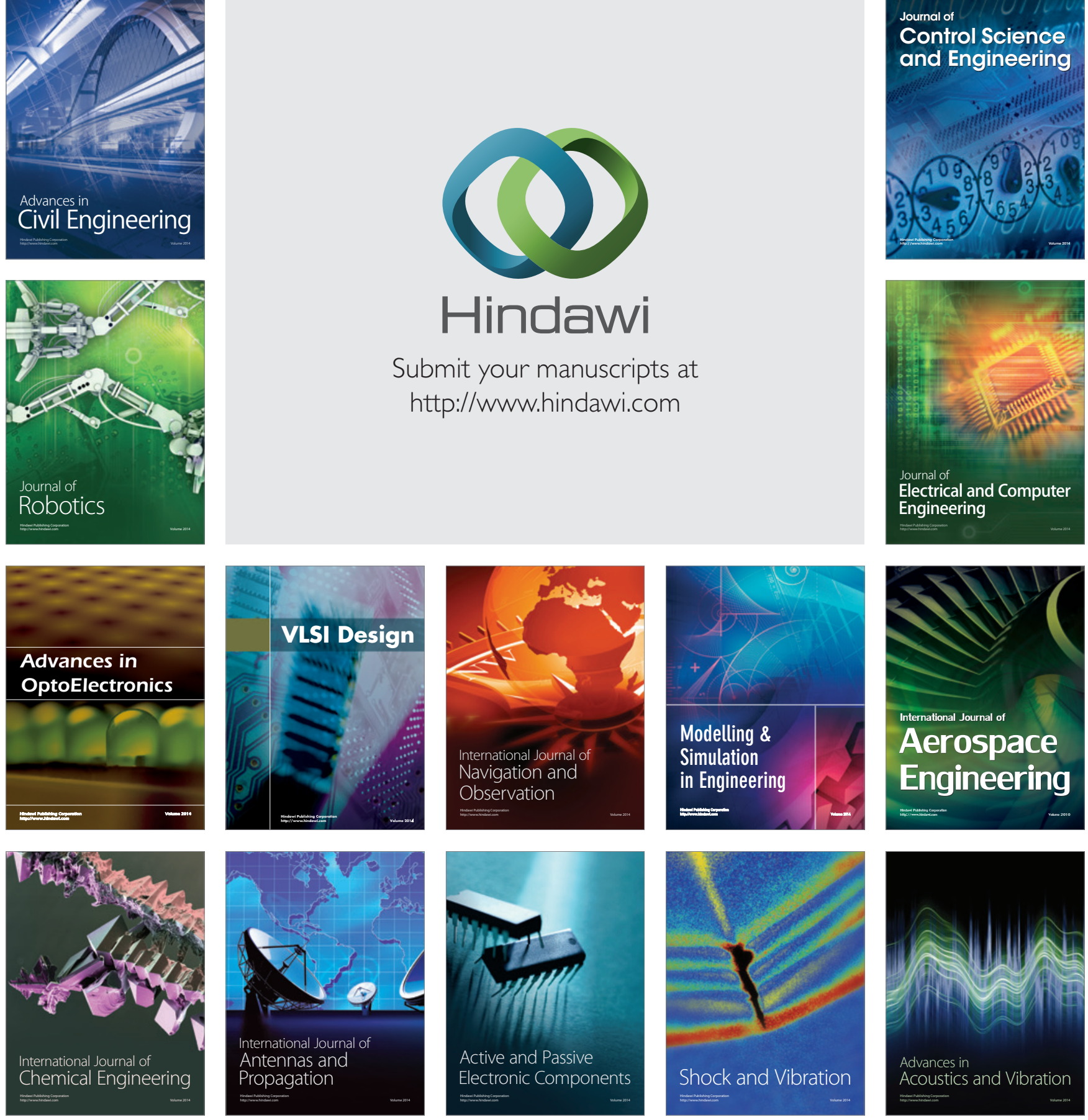